\title{
miR-212 mediates counter-regulation on CRH expression and HPA axis activity in male mice
}

\author{
Yuxiao Tang1,*, Xingjian Cai1,*, Hongwei Zhang1,*, Hui Shen1, Wanyin Wang1, \\ Zhilei Shen', Wei Gu2 ${ }^{2}$, Changquan Ling ${ }^{2}$ and Min Li1
}

${ }^{1}$ Military Hygiene Department, Faculty of Naval Medicine, Second Military Medical University, Shanghai, China 2Department of Traditional Chinese Medicine, Changhai Hospital, Second Military Medical University, Shanghai, China *(Y Tang, $\mathrm{X}$ Cai and $\mathrm{H}$ Zhang contributed equally to this work)
Correspondence should be addressed to $\mathrm{C}$ Ling or $\mathrm{M} \mathrm{Li}$ Email lingchangquan@hotmail.com or limin@smmu.edu.cn

\begin{abstract}
The mechanisms of hypothalamic-pituitary-adrenal (HPA) axis regulation have been studied persistently but still are not elucidated. Considering the emerging roles of microRNA in stress response, we conducted a microRNA microarray in mice hypothalamus to identify the potential role of microRNAs in regulating the HPA axis. In total, 41 microRNAs changed during heat stress in which we found that miR-212 contains a binding sequence with corticotropin-releasing hormone (Crh) 3'UTR according to a sequence analysis. We observed that miR-212 expression in the hypothalamus was escalated by repeated heat and restraint stress. By overexpression or inhibition of miR-212 and the dual-luciferase reporter assay, we proved that miR-212 could bind with Crh 3'UTR to regulate its expression in mice hypothalamus primary cells and in the hippocampus neuron cell line HT-22. In addition, we injected miR-212 agomir or antagomir in mice hypothalamus to overexpress or inhibit miR-212, which leads to alterations of $\mathrm{CRH}$ expression and HPA axis activity in vivo. Furthermore, miR-212 and $\mathrm{CRH}$ were both transcribed by the CAMP response element-binding protein (CREB). Overexpression and inhibition of miR-212 affect CREB-dependent CRH expression. Taken together, our results suggest an inhibitory role of miR-212 on the HPA axis, which acts in a counter-regulatory manner.
\end{abstract}
Key Words
- microRNA
- HPA axis
- hypothalamus
- counter-regulatory pathway

Journal of Molecular

Endocrinology

(2017) 59, 365-375

\section{Introduction}

The hypothalamic-pituitary-adrenal (HPA) axis plays a pivotal role in prompting management, adaptation and recovery from stress (Sapolsky et al. 2000, de Kloet et al. 2005, McEwen 2007). It is well documented, however, that overactivity of the HPA axis is accompanied by impaired physical functions, including growth, metabolism, circulation, reproduction, inflammation and immunity (Charmandari et al. 2005, Chrousos \& Kino 2007, Nicolaides et al. 2015). The mechanisms of the HPA axis regulation continue to intrigue researchers (McEwen 1998, 2008, Glaser \& Kiecolt-Glaser 2005, Reynolds 2013). As the starting point of the HPA axis, corticotropinreleasing hormone $(\mathrm{CRH})$ is a key element in managing HPA axis activity, and numerous researchers have studied its regulation extensively (Kovacs 2013). The dominant way by which $\mathrm{CRH}$ is regulated is through the negative feedback of glucocorticoids (GC) (Herman et al. 2016). Other factors also seem to be involved, however, as

Published by Bioscientifica Ltd 
treatment with GC in adrenalectomized rats does not prevent an increase in stress-induced CRH hnRNA (Kageyama \& Suda 2009). In addition, a decline in CRH after stress exposure is independent of circulating GC because adrenalectomized rats, which lack GC, display an identical pattern (Shepard et al. 2005). Aside from GC, many negative regulating factors of CRH have been identified so far, including GABAergic neurons (Gunn et al. 2015), endocannabinoid signaling (Hill \& Tasker 2012) and inflammatory cytokines (Felger \& Lotrich 2013). The network of transcription factors and co-regulators of regulation of CRH expression, however, remain to be explored (Kovacs 2013).

Since their discovery, microRNAs have been found to be involved in various biological processes and usually function as negative regulators through post-transcription regulation by binding target mRNA to inhibit mRNA translation or facilitate mRNA degradation (Zeng et al. 2002, Bartel 2004). Recently, it has been indicated that microRNAs participate in stress response (Leung \& Sharp 2010, Hollins \& Cairns 2016). A study reported that adult male rats subjected to both acute and chronic restraint stresses show altered expressions of numerous miRNAs in the brain (Meerson et al. 2010). More specifically, Rinaldi et al. found that expressions of let-7a, miR-9 and $\mathrm{miR}-26 \mathrm{a} / \mathrm{b}$ increase in the frontal cortex in acute-restraint stress mice (Rinaldi et al. 2010). Furthermore, several studies have reported that alterations of microRNA expression, induced by stress, indirectly affect regulation of HPA axis activity. An in vitro study demonstrates that miR-34c reduces the responsiveness of cells to CRH by regulating corticotrophin-releasing hormone receptor 1 (CRHR1) (Haramati et al. 2011). Additionally, miR-449a contributes to CRHR1 downregulation induced by GC in the pituitary during stress (Nemoto et al. 2013). Another proof is disclosed by the finding that the GC receptor is regulated by miR-18 and miR-124 in the brain (Vreugdenhil et al. 2009). Nevertheless, direct connections between microRNAs and regulation of the HPA axis are absent. Whether the CRH expression is regulated by microRNAs in the hypothalamus remains unknown.

To this end, our study investigates the potential role of microRNAs in regulating CRH and HPA axis activity. By using a microRNA microarray in the hypothalamus and conducting subsequent validation experiments, we prove that miR-212 can bind with Crh 3'UTR to regulate its expression in a counter-regulatory manner in vitro and can further affect HPA axis activity in vivo. On the basis of our findings, we propose a new perspective of HPA axis regulation, which may be helpful for developing gene therapy interventions for patients with HPA axis overactivity diseases.

\section{Materials and methods}

\section{Animals}

We purchased male C57BL/6 (8 weeks old) mice from Slac Laboratory Animal (Shanghai, China) and maintained at $22 \pm 2^{\circ} \mathrm{C}, 12 \mathrm{~h}$ light/12 $\mathrm{h}$ dark cycle (07:00 light on/19:00 light off) with food and water freely available. We conducted all animal experiments in accordance with the 'Guide for the Care and Use of Laboratory Animals', and with the approval of the Second Military Medical University Institutional Animal Care and Use Committees.

\section{Repeated stress process}

After being acclimated for 1 week, 40 mice weighing approximately $22 \pm 2 \mathrm{~g}$ were divided randomly into five groups $(n=8)$ for repeated heat stress, including day 0 (without exposure), day 1 (exposed 1 time), day 3 (exposed 3 times), day 7 (exposed 7 times) and day 14 (exposed 14 times). We also randomly divided another 40 mice in the same batch into five groups for repeated restraint stress with an identical set of groups. Details of the stress procedures are as follows: (1) Heat stimulus: mice were placed in an artificial climate cabin with a temperature of $40^{\circ} \mathrm{C}$ and relative humidity of $60 \%$ for $1 \mathrm{~h}$; (2) immobilization: mice were placed in a $50-\mathrm{mL}$ centrifuge tube $(28 \mathrm{~mm}$ diameter $\times 105 \mathrm{~mm}$ long) with a punching hole for $1 \mathrm{~h}$. All experiments were conducted between 09:00 h and 10:00 h every day. We decapitated the mice at the end of exposure, and then we immediately collected the blood and hypothalamus. We centrifuged the blood at $3000 \boldsymbol{g}$ for $20 \mathrm{~min}$ to obtain serum for adrenocorticotropic hormone (ACTH) and corticosterone (CORT) detection. We used the hypothalamus to extract RNA and protein for real-time polymerase chain reaction (PCR) and Western blot.

\section{MicroRNA microarray and data analysis}

We obtained the hypothalamus from another 15 decapitated mice at day 0, day 1 and day 7 (five mice in each group). We abstracted a total of 15 RNA samples by using Trizol reagent (Catalog \#15596-026, Invitrogen), which we processed in an Affymetrix GeneChip miRNA3.0 (Catalog \#902017, Invitrogen) to profile the patterns of microRNA http://jme.endocrinology-journals.org DOI: 10.1530/JME-17-0124
๑) 2017 Society for Endocrinology Printed in Great Britain
Published by Bioscientifica Ltd 
expression. The random-variance model (RVM, which is commonly used for comparison of more than two groups) $F$-test was applied to filter the differentially expressed microRNAs for the three groups because the RVM F-test can raise degrees of freedom effectively in small samples. After conducting analyses to determine significance and the false discovery rate, we selected the differentially expressed microRNAs according to the $P$ value threshold (Wright \& Simon 2003, Clarke et al. 2008).

\section{Injection of miR-212 agomir and antagomir in mice hypothalamus}

We injected microRNAs agomir and antagomir to the local site for functional research (Hou et al. 2011). We divided the 45 mice weighing between $26 \mathrm{~g}$ and $28 \mathrm{~g}$ into five groups (day $0,1,3,7$ and 14), and each group had three subgroups $(n=3)$, which we injected with $2 \mu \mathrm{L}$ negative control, miR-212 agomir and miR-212 antagomir (Genepharma, Shanghai, China) at a concentration of $1 \mathrm{OD} / \mu \mathrm{L}(\sim 2.5 \mathrm{nmol} / \mu \mathrm{L})$ in the paraventricular nucleus PVN, respectively. We completed the injection by mouse brain stereotaxic apparatus. The injection coordinates were $0.82 \mathrm{~mm}$ caudal and $0.1 \mathrm{~mm}$ lateral from Bregma and $4.75 \mathrm{~mm}$ ventral from the surface of the skull at Bregma, according to Paxinos \& Franklin (2003).

\section{Determination of serum hormone concentrations}

We measured serum ACTH andCORTby radioimmunoassay kits (Catalog \#D14DJB and Catalog \# D10PJB, North Institute of Biological Technology Co. Beijing, China) following the manual protocol.

\section{Mice hypothalamic primary cells and HT-22 cells}

We purchased primary cells of mice hypothalamus and HT-22 cells, a kind of mice hippocampus neuron cell line, with identification reports from Zhongqiaoxinzhou Biotech Inc. (Shanghai, China) and cultured the cells in the primary neurons' culture system (Catalog \#PriMed-iCell-005, iCell, Shanghai, China) with precoated poly-L-lysine or in Dulbecco's Modified Eagle Medium (Catalog \#SH30022.01B, HyClone; GE Healthcare) supplemented with 10\% fetal bovine serum (Catalog \#10099-141, Gibco Laboratories) and $1 \%$ antibiotic solution (Catalog \#15140-122, Gibco Laboratories) and incubated the cells in a humidified $5 \%$ carbon dioxide atmosphere at $37^{\circ} \mathrm{C}$.

http://jme.endocrinology-journals.org DOI: 10.1530/JME-17-0124

\section{Transfection}

For hypothalamic primary cell transfection, we used miR-212 agomir and antagomir (Genepharma) at a concentration of $50 \mathrm{nM}$ and $100 \mathrm{nM}$, respectively. For HT-22 transfection, we used miR-212 mimics and inhibitors (Genepharma) at a concentration of $50 \mathrm{nM}$ and $100 \mathrm{nM}$, respectively. We transfected plasmids for cAMP response element-binding protein (CREB; Genepharma) at a concentration of $3 \mu \mathrm{g} / \mathrm{mL}$. We performed all transfections by using micropoly-transfecter cell reagent (Catalog \#MT115, Micropoly, NanTong, China), and extracted RNA and protein $48 \mathrm{~h}$ after the transfection for downstream experiments.

\section{Dual-Luciferase reporter assay}

We grew HT-22 cells on 96 -well plates to approximately $50 \%$ confluence and co-transfected plasmids of GP-miRGLO (Genepharma) containing either the wild-type or mutated Crh 3'UTR with miR-212 mimics or negative control. Forty-eight hours after transfection, the cells underwent lysis for luciferase activity with a Dual-Luciferase Reporter Assay System (Catalog \#E1910, Promega). We normalized firefly luciferase activity to Renilla luciferase activity for each cell culture.

\section{Total RNA and protein extracted from mice hypothalamus and cells}

Because of the small size of mice hypothalamus, we used All-In-One DNA/RNA/Protein Mini-preps Kit (Catalog \#B618003, Sangon Biotech, Shanghai, China) to extract RNA and protein simultaneously. In general, after tissue homogenization and lysis, we centrifuged the liquid in an RNA purification column to obtain RNA and added the flow-through with protein precipitation solution to precipitate protein. In cells, we extracted RNA by Trizol reagent (Catalog \#15596-026, Invitrogen) and extracted protein using a whole-protein extraction kit (Catalog \#KGP250, Keygene, Nanjing, China).

\section{Real-time quantitative PCR analysis}

We reverse-transcribed $1 \mu \mathrm{g}$ RNA of each sample to cDNA using a Reverse-Transcription Reagent Kit (Catalog \#RR036A \& \#RR037A, Takara Bio). We performed real-time quantitative PCR amplification with the SYBR Green Kit (Catalog \#QPK-201, Toyobo Bio Inc., Osaka,

Published by Bioscientifica Ltd. 
Japan) using the StepOnePlus (Applied Biosystems). We normalized the mRNA expression of the target gene to 18 s and normalized miRNA to U6. We used the following primers: 18s-forward, GTAACCCGTTGAACCCCATT; 18s-reverse, CCATCCAATCGGTAGTAGCG; Crhforward, TCTCACCTTCCACCTTCTGC; $\mathrm{Crh}$ reverse, AAGCGCAACATTTCATTTCC; Creb-forward, TGCCAACTCCAATTTACCAA and Creb-reverse, ACCCCATCGGTACCATTGTT. We purchased the primer set for U6 and miR-212 from Genepharma.

\section{Western blot}

We separated $30 \mu \mathrm{g}$ denatured proteins by electrophoresis in SDS-page gel and transferred the proteins to the polyvinylidene difluoride membrane (Catalog \#BSP0161, PALL Life Science, Port Washington, NY, USA) using the Bio-Rad system. We purchased the following antibodies from Abcam: anti-CRH antibody (Catalog \#ab184238), anti-CREB antibody (Catalog \#ab32515), anti-CREB (Phospho-S133, Catalog \#ab32096) and anti- $\beta$-actin (Catalog \#D110001, Sangon Biotech, Shanghai, China). We normalized grayscales of target protein, measured by GeneSnap from SynGene software package, to $\beta$-actin.

\section{Statistics}

We represented the data as mean \pm S.E.M. The statistical difference between the two groups was assessed by an independent $T$-test. We performed one-way analysis of variance, followed by a Bonferroni test as the posttest, to analyze differences among the three or more groups. Differences were considered significant at the 95\% confidence level $(P<0.05):{ }^{*} P<0.05,{ }^{* *} P<0.01$, and

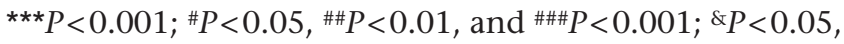
$\& \& P<0.01$, and $\& \& \& P<0.001$; and $\$ P<0.05, \$ \$ P<0.01$, and $\$ \$ P<0.001$.

\section{Results}

\section{Hypothalamic miR-212 expression was escalated in mice exposed to repeated stress}

To observe changes of hypothalamic microRNAs expression in mice exposed to repeated stress, we used Affymetrix GeneChip miRNA3.0 to investigate the expression pattern of microRNAs in the hypothalamus during heat stress as described in the Materials and methods section. Among all the microRNAs detected, we identified 41 microRNAs with significant changes and a cluster analysis was exhibited in Fig. 1A. Through sequence-matching analysis of these 41 microRNAs, we identified 1136 target genes in three microRNA databases: Targetscan, miRdb and miRanda. The most relevant gene ontology and pathway pertaining to these genes were the DNA-dependent regulation of transcription and the PI3K-Akt signaling pathway, respectively. We did find the direct link between the microRNA and the HPA axis in which miR-212-5p could bind with Crh 3'UTR at position 284-290 (Fig. 2E) according to Targetscan. The expression of miR-212 increased gradually at day 1 and day 7 compared with day 0 in the microarray.

To elucidate changes of miR-212 expression and HPA axis activity, we conducted two repeated stress processes on mice and added two groups: day 3 and day 14. Results showed that miR-212 expression escalated by the amount of time exposed to stress, whereas $\mathrm{Crh}$ expression was enhanced in the mice that were exposed to the stimulus at day 1 and climaxed at around day 3. Subsequently, the Crh expression showed a significant decrease at day 7 and day 14 in both heat and restraint stress models (Fig. 1B and $\mathrm{C}$ ) as well as protein level (Fig. 1E and F). In addition to the CRH expression in the hypothalamus, the serum content of ACTH and CORT exhibited identical alterations (Fig. 1D and G) in both models, which indicated that the inhibitory mechanisms of HPA axis produced effects at day 7 and day 14 .

Because of the inverse relationship between a gradual increase in miR-212 and a subsequent decrease in HPA axis activity in mice subjected to repeated stress, and more meaningfully, considering potential binding site for miR-212 exists in Crh 3'UTR, we hypothesized that miR-212 may bind with Crh and could be involved in regulating its expression and HPA axis activity during repeated stress.

\section{miR-212-regulated CRH expression in primary cells of mice hypothalamus and hippocampus cell HT-22}

To explore whether miR-212 had a role in regulating the CRH expression, we first observed changes of $\mathrm{Crh}$ expression in primary hypothalamic cells after overexpression or inhibition of miR-212. Hypothalamic primary cells extracted from mice were identified by immunofluorescence using the neuron specific enolase antibody. The purity of these primary cells was greater than 95\% according to the analysis of immunofluorescence (Fig. 2A). As shown in Fig. 2B, overexpression of miR-212 by miR-212 agomir transfection decreased

Published by Bioscientifica Ltd. 
A

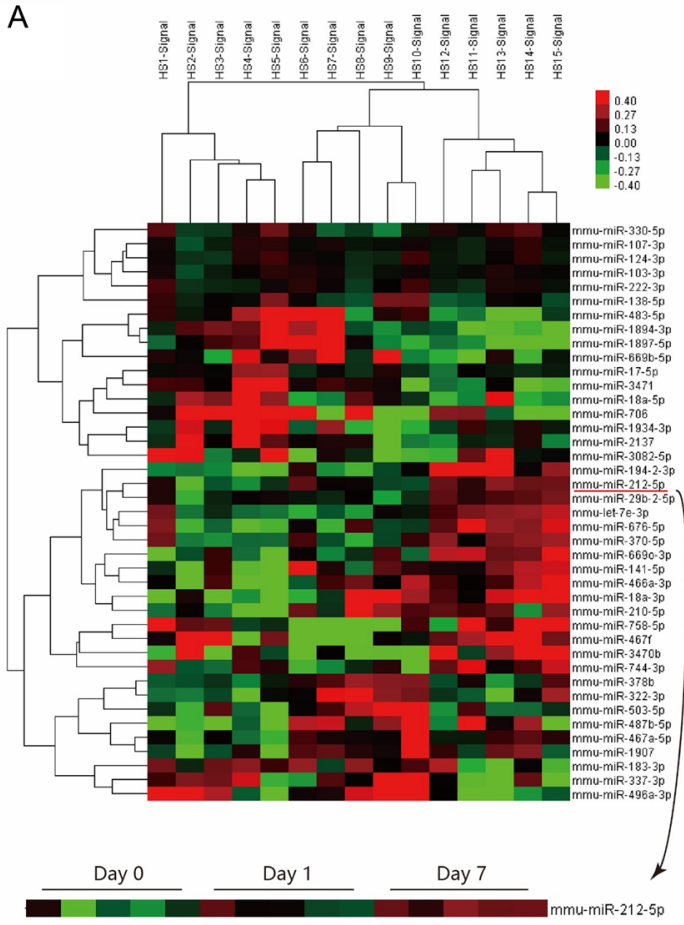

B

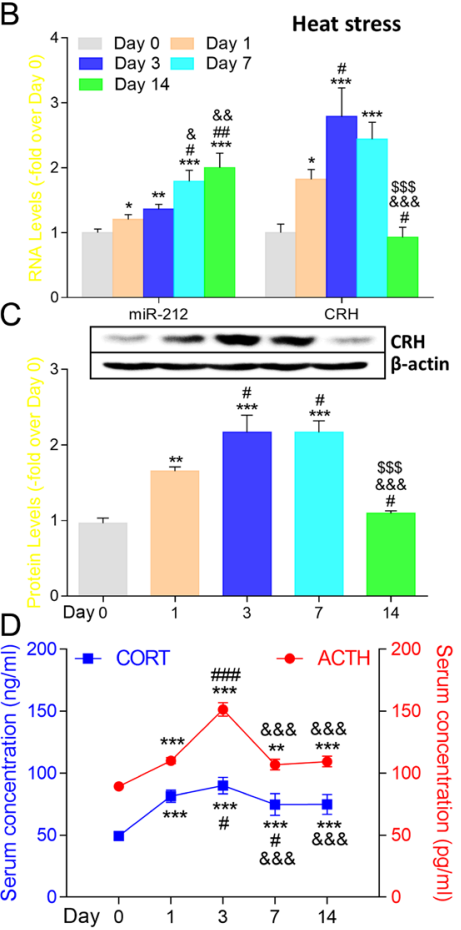

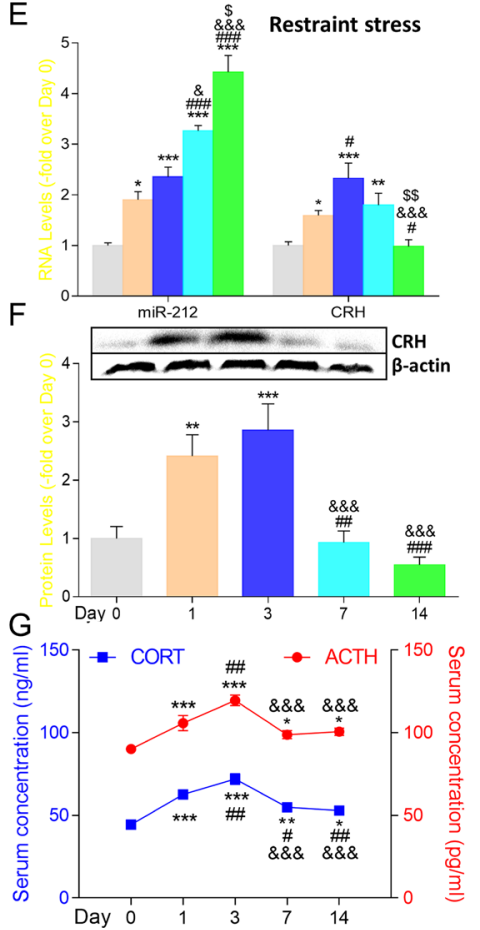

Figure 1

Hypothalamic miR-212 expression was escalated in mice exposed to repeated stress. (A) Cluster analysis of 41 significantly changed microRNAs in the hypothalamus of heat-exposed mice ( $n=5$ in groups of day 0,1 and 7). (B) miR-212 and CRH mRNA expressions $(n=8)$ in a 14-day heat stress process. (C) CRH protein expression in a 14-day heat stress. Grayscale of CRH protein bands normalized to $\beta$-actin. (D) Serum contents $(n=8)$ of ACTH and CORT in a 14-day heat stress process. (E) miR-212 and CRH mRNA expressions $(n=8)$ in a 14-day restraint stress process. (F) CRH protein expression in a 14-day restraint stress process. (G) Serum contents $(n=8)$ of ACTH and CORT in a 14-day restraint stress process. Data were presented as mean \pm s.E.M. $* P<0.05$, ${ }^{* *} P<0.01$, and ${ }^{* *} * P<0.001$ (vs group of day 0 ); ${ }^{*} P<0.05,{ }^{\#} P<0.01$, and $\# \# P<0.001$ (vs group of day 1 ); $\& P<0.05$, \&\& $P<0.01$, and \&\&\&P<0.001 (vs group of day 3); and $\$ P<0.05$, $\$ P<0.01$, and $\$ \$ P<0.001$ (vs group of day 7). A full color version of this figure is available at http://dx.doi.org/10.1530/JME-17-0124.

mRNA expression of $\mathrm{Crh}$, whereas inhibition of miR-212 by miR-212 antagomir transfection increased mRNA expression of Crh.

We used the cell line HT-22, a kind of hippocampus cell that also expresses CRH, to conduct a dual-luciferase reporter assay to further identify the binding activity of miR-212 and Crh 3'UTR. At first, we proved that transfection with miR-212 mimics could decrease mRNA and the protein expression of CRH and miR212 inhibitors could increase mRNA and protein expression of CRH (Fig. 2C and D). Next, we constructed GP-miRGLO plasmids that contained either a wildtype or mutated binding site in Crh 3'UTR for miR-212 (Fig. 2E). The result of the dual-luciferase reporter assay showed that co-transfection with wild-type plasmids and miR-212 mimics could significantly reduce the relative luciferase activity (firefly luminescence and Renilla luminescence); however, when the binding site was mutated, the effect of the miR-212 mimics disappeared (Fig. 2F). Taken together, our results showed that
miR-212 could bind directly to Crh 3'UTR and could regulate the $\mathrm{CRH}$ expression in vitro.

\section{A counter-regulatory pathway mediated by miR-212 to inhibit CRH expression in vitro}

It has been reported that CREB-responsive elements in both miR-212 and $\mathrm{CRH}$ promoters are required for pCREB-dependent transcription of miR-212 in primary cortical neurons and THP-1 monocytes (Remenyi et al. 2010, Nahid et al. 2013) and CRH in response to stress (Seasholtz et al. 1991, Kovacs \& Sawchenko 1996, Kovacs 2013). This finding inspired our curiosity to determine the underlying mechanism since we observed that miR-212 and CRH displayed different expression patterns in the hypothalamus after stress (Fig. 1). To explore this, we first observed the expression of CREB in the hypothalamus. Results showed that mRNA expression (Fig. 3A), protein expression and phosphorylation level of CREB in both heat stress (Fig. 3B) and restraint stress (Fig. 3C) had the http://jme.endocrinology-journals.org DOI: 10.1530/JME-17-0124
() 2017 Society for Endocrinology Printed in Great Britain 
A

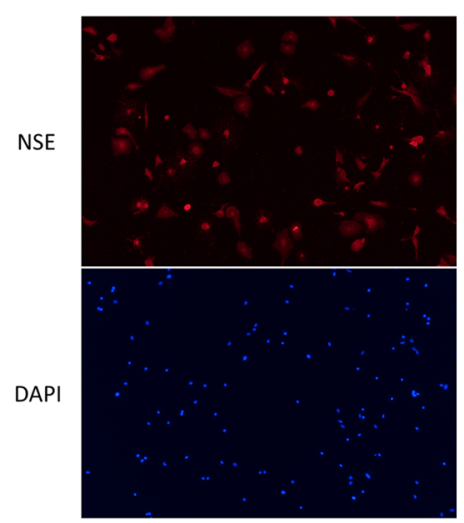

C

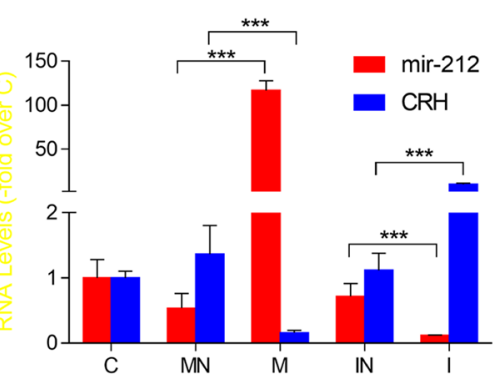

B

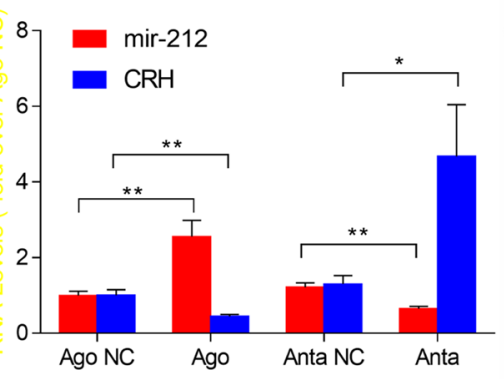

D

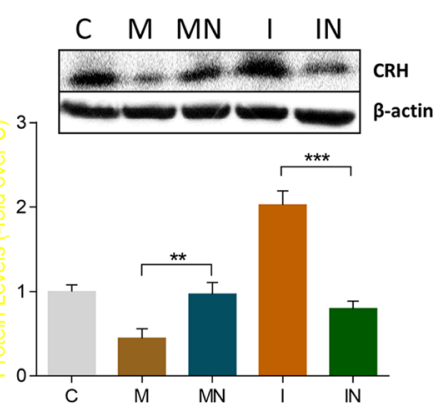

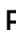

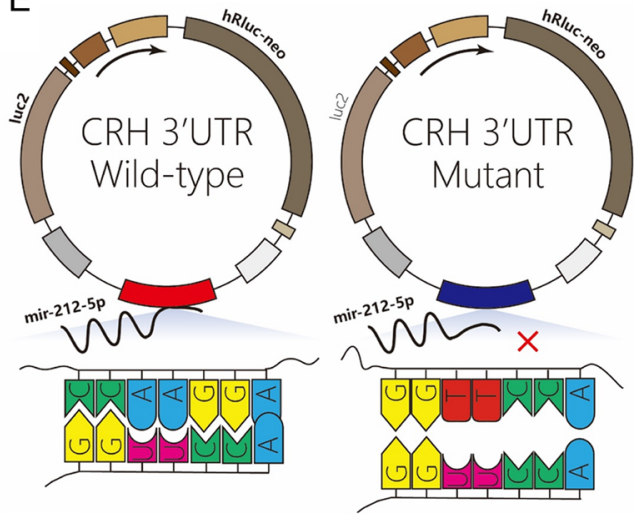

$\mathrm{F}$

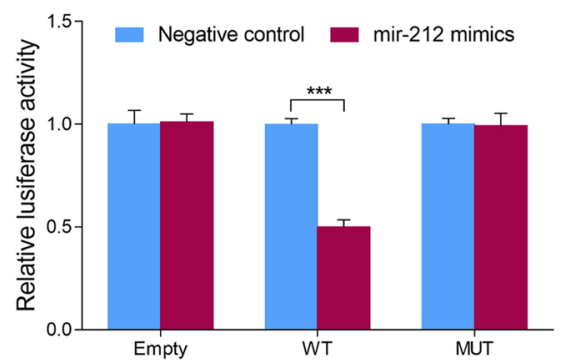

Figure 2

miR-212-regulated CRH expression via direct binding in hypothalamic primary cells and HT-22 cells. (A) Identification of primary hypothalamic cells by immunofluorescence using NSE antibody. The purity of these primary cells was more than $95 \%$. (B) Transfecting hypothalamic primary cells with miR-212 agomir led to a decrease in the CRH mRNA expression, whereas miR-212 antagomir led to an increase in the CRH mRNA expression. Ago NC, negative control of miR-212 agomir; Ago, miR-212 agomir; Anta NC, negative control of miR-212 antagomir; Anta, miR-212 antagomir. (C) Transfecting miR-212 mimics to HT-22 cells led to a decrease in CRH mRNA, whereas miR-212 inhibitors led to an increase in CRH mRNA. C, blank control; MN, miR-212 mimics negative control; M, miR-212 mimics; IN, miR-212 inhibitors negative control; I, miR-212 inhibitors. (D) Effects of miR-212 mimics and inhibitors transfection on the protein expression of CRH were consistent with the mRNA expression. (E) Binding sequences of wild-type and mutant CRH $3^{\prime}{ }^{\prime} \mathrm{CTR}^{\prime}$ with miR-212-5p in GP-miRGLO plasmids. (F) Relative luciferase activity of co-transfection of (1) empty plasmids (empty) and miR-212 mimics or negative control; (2) wild-type CRH 3'UTR plasmids (WT) and miR-212 mimics or negative control and (3) mutant CRH 3'UTR plasmids (MUT) and miR-212 mimics or negative control. miR-212 mimics led to a decrease in relative luciferase activity of wild-type plasmid, but this effect disappeared as a result of a mutated binding sequence. Data were presented as mean \pm S.E.M. ${ }^{*} P<0.05, * * P<0.01$, and $* * * P<0.001$. A full color version of this figure is available at http://dx.doi.org/10.1530/JME-17-0124.

same trend as miR-212. The CRH expression, however, increased at first and subsequently decreased under the condition that CREB persistently increased during repeated stress process.

To observe the role of miR-212 in CREB-dependent CRH expression, we used HT-22 cells for transfection and set 5 groups: blank control (C), negative control of CREB plasmids (NC), CREB overexpression plasmids (CR), co-transfection of CREB plasmids and miR-212 mimics (CRM), and co-transfection of CREB plasmids and miR-212 inhibitors (CRI). Transfection with CREB plasmids resulted in an increase in CREB, miR-212 and $\mathrm{CRH}$ (Fig. 3D and $\mathrm{E}$; the group of CR), which meant that CREB was a transcriptional activator of miR-212 and CRH gene expressions, which is in accordance with other research works (Remenyi et al. 2010, Kovacs 2013, Nahid et al. 2013). Co-transfection of CREB plasmids and miR-212 mimics reduced the increase in the CRH expression, whereas miR-212 inhibitors amplified the role of CREB overexpression on the CRH expression compared with the group that had only CREB overexpression (Fig. 3D and E; the group of CRM and CRI). Thus, we thought that miR-212 acted in a counter-regulatory way to prevent the overexpression of CRH when CREB was activated during stress.

\section{miR-212-regulated CRH expression and further affected HPA axis activity in vivo}

To observe the effects of miR-212 on CRH expression and HPA axis activity in vivo, we overexpressed or inhibited miR-212 in the hypothalamus through injection of miR-212 agomir or antagomir. At first, we observed that injection of miR-212 agomir could significantly increase

Published by Bioscientifica Ltd 
A

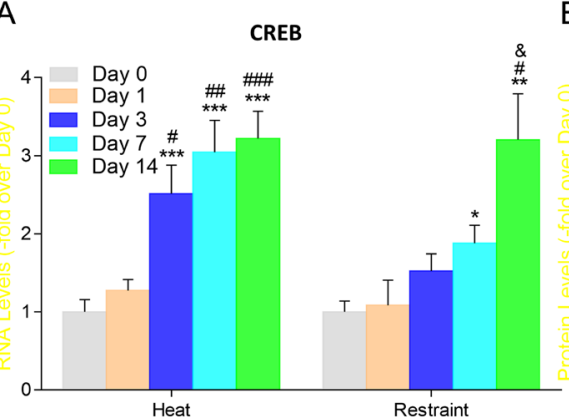

B

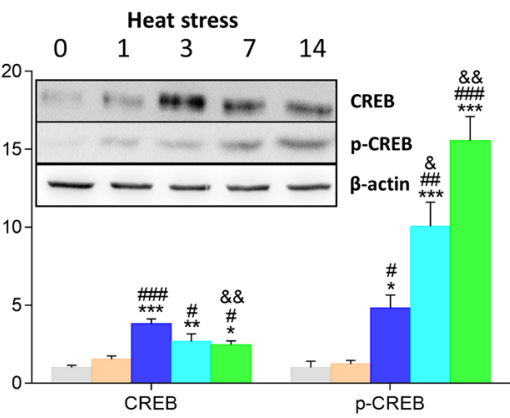

C

D

E
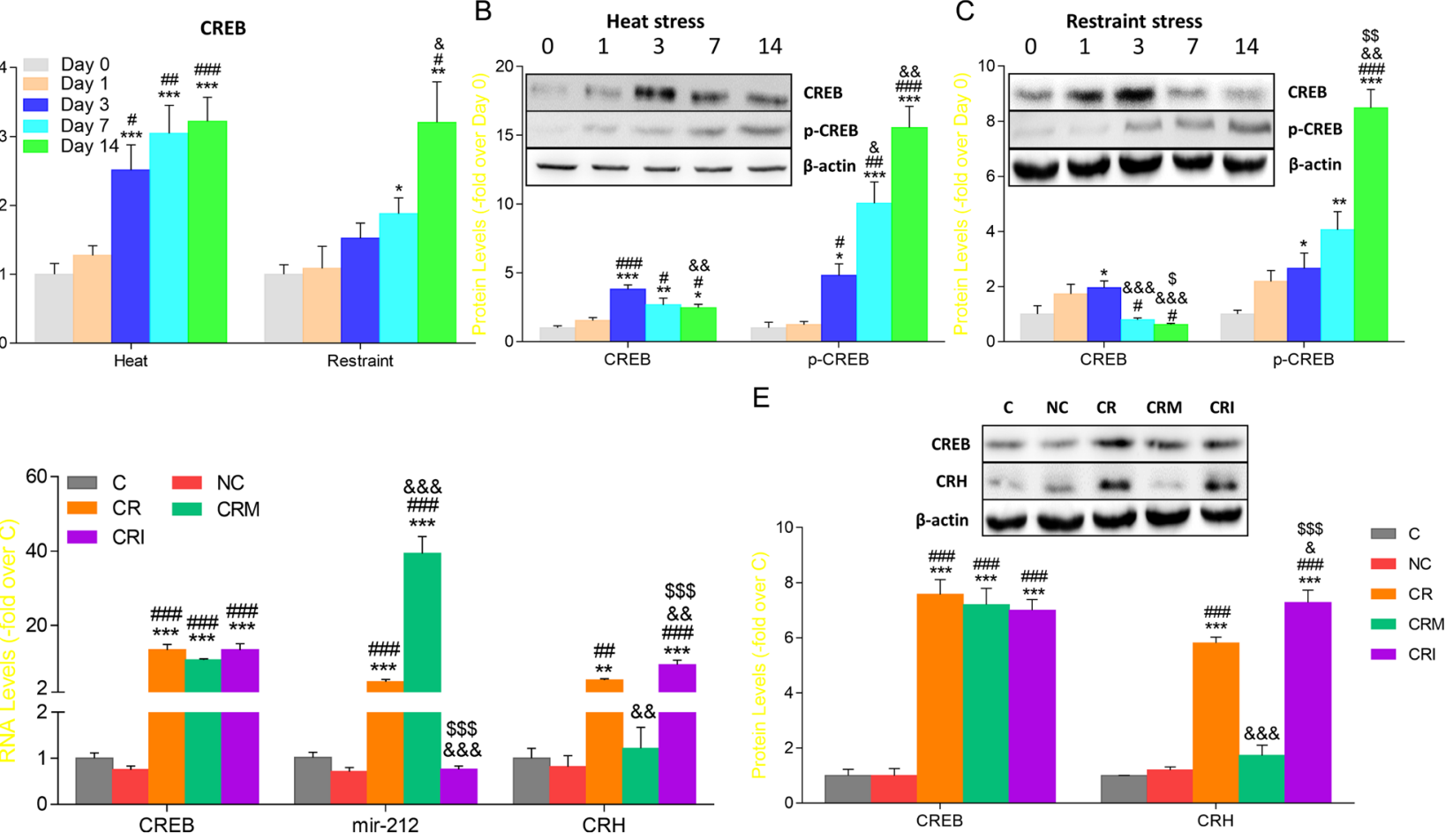

Figure 3

CREB-mediated CRH expression was regulated by miR-212. (A) Effects of heat-restraint stress on the expression of CREB mRNA ( $n=8)$ in a 14-day repeated stress process. (B) Protein expression of CREB and p-CREB in the heat stress process $(n=3)$. (C) Protein expression of CREB and p-CREB in the restraint stress process $(n=3)$. Data were presented as mean \pm S.E.M. ${ }^{*} P<0.05, * * P<0.01$, and $* * * P<0.001$ (vs group of day 0 ); $\# P<0.05$, $\# P<0.01$, and $\# \# P<0.001$ (vs group of day 1); $\& P<0.05$, \&\&P<0.01, and \&\&\&P<0.001 (vs group of day 3 ); and $\$ P<0.05, \$ \$ P<0.01$, and $\$ \$ P<0.001$ (vs group of day 7 ). (D) In HT-22 cells, overexpression of CREB (CR) led to an increase in miR-212 and CRH mRNA compared with group of control (C) or negative control (NC), co-transfection of CREB plasmids and miR-212 mimics (CRM) inhibited the increase in CRH mRNA, whereas co-transfection of CREB plasmids and miR-212 inhibitors (CRI) amplified the increase in CRH mRNA compared with the group of CR. (E) Changes of CRH and CREB protein resulted from co-transfection of CREB plasmids and miR-212 mimics or miR-212 inhibitors in HT-22 cells. Data were presented as mean \pm S.E.M. $* P<0.05, * * P<0.01$, and $* * * P<0.001$ (vs group of $\mathrm{C}$ ); $\# P<0.05, \# P<0.01$, and $\# \# P<0.001$ (vs group of $\mathrm{NC}$ ); $\& P<0.05$, \&\&P$<0.01$, and \&\&\&P<0.001 (vs group of $\mathrm{CR}$ ); $\$ P<0.05, \$ \$ P<0.01$, and $\$ \$ P<0.001$ (vs group of CRM). A full color version of this figure is available at http://dx.doi.org/10.1530/JME-17-0124.

the miR-212 expression in hypothalamus. Meanwhile, CRH expression and HPA axis activity decreased after one-time heat stimulus (data not shown). After that, we conducted a 14-day heat stress process on mice by injecting a negative control, miR-212 agomir or miR-212 antagomir into the hypothalamus.

During repeated stress, mice injected with miR-212 agomir or antagomir showed a significant increase or decrease in miR-212 in the hypothalamus (Fig. 4A). Consistent with the results of experiments in vitro, overexpression of miR-212 decreased the CRH expression and inhibition of miR-212 increased the CRH expression at both mRNA and protein levels (Fig. 4B, D and E). CREB and pCREB levels increased gradually during repeated stress, independent of the injection (Fig. 4C, D, F and G). A more meaningful result was that injection of miR-212 agomir led to a decreased serum content of ACTH and CORT compared with injection of the negative control
(Fig. 4H), whereas injection of miR-212 antagomir augmented the stress response with an increased serum content of ACTH and CORT (Fig. 4I). Taken together, these results demonstrate that miR-212 could modulate $\mathrm{HPA}$ axis activity by regulating the $\mathrm{CRH}$ expression in vivo.

\section{Discussion}

Much is known about CRH regulation to date, and many aspects of the inhibitory mechanisms of CRH have been elucidated, including the following two main aspects: (1) negative feedback, which includes GC negative feedback (Di et al. 2003, Evanson et al. 2010), ACTH negative feedback (Silverman \& Sternberg 2012) and negative feedback of other hormone or cytokine (Uchoa et al. 2014); and (2) counter-regulation, including an inhibitory neuron projecting to the PVN (Evanson \& Herman 2015), an inhibitory factor inducible cyclic AMP 
B
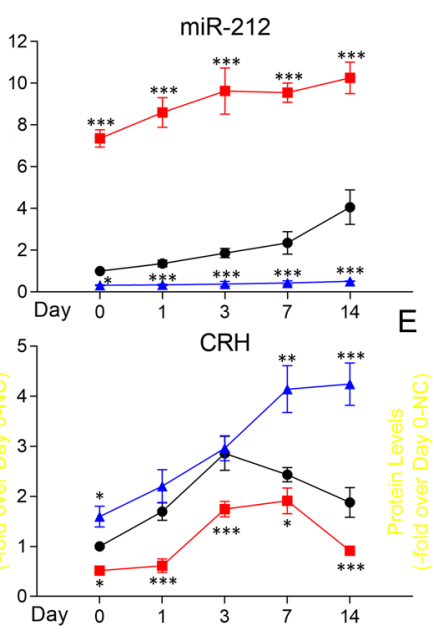

C

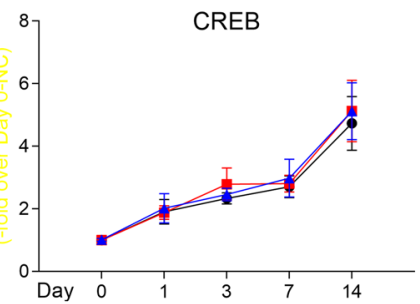

- Negative control

- Agomir

- Antagomir

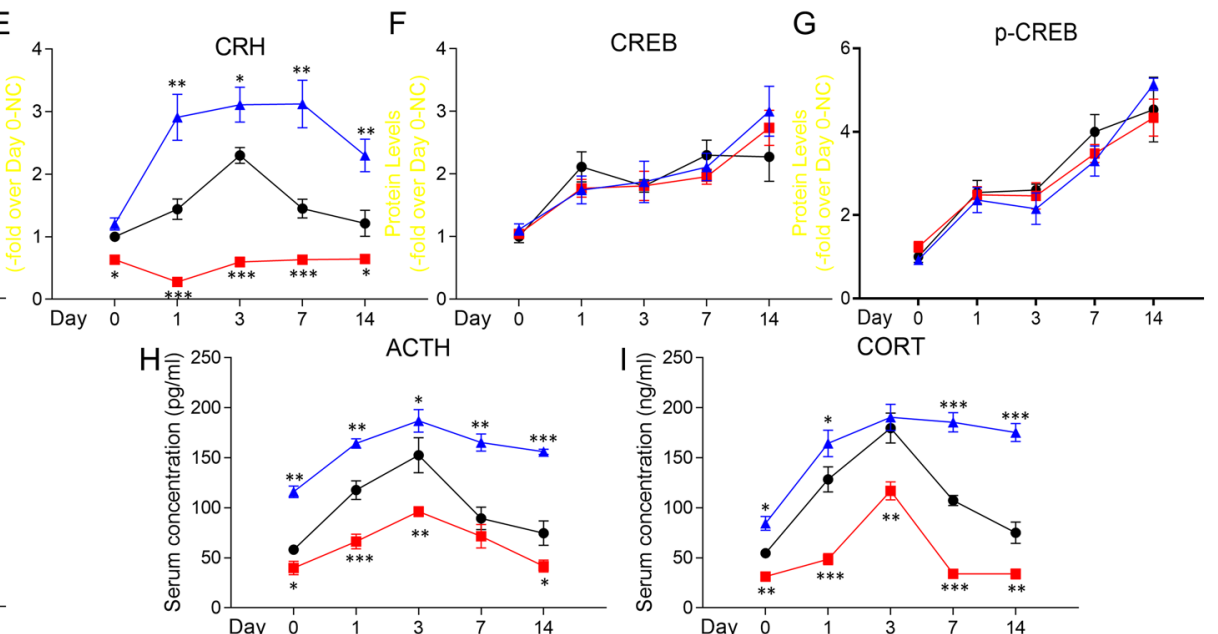

D
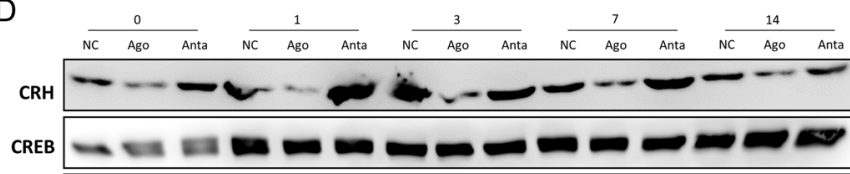

p-CREB

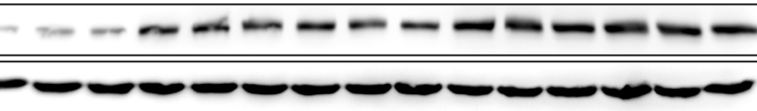

F
G

Figure 4

Effects of overexpression or inhibition of miR-212 on CRH expression and HPA activity in mice exposed to the heat stress process. (A) miR-212 expression in mice hypothalamus. Injection of miR-212 agomir significantly increased the miR-212 expression in the hypothalamus, whereas injection of miR-212 antagomir had an inhibitory effect. (B) Effects of miR-212 agomir and antagomir on the mRNA expression of CRH during the 14-day heat stress process. In mice injected with negative control, level of CRH mRNA increased at beginning and returned to baseline at the end. Compared to group of the negative control, the miR-212 agomir injection group showed a significant decrease in the CRH mRNA expression. At the same time, the miR-212 antagomir injection group showed an increase in the CRH mRNA expression. (D and E) The protein expression of CRH was in accord with the mRNA expression. (C) The CREB mRNA expression was escalated during the stress process independent of the miR-212 injection, as well as the protein expression of CREB and p-CREB (D, F and G). (H and I) Effects of miR-212 agomir and antagomir injection on serum contents of ACTH and CORT. Like CRH expression in the hypothalamus, serum contents of ACTH and CORT were also regulated by miR-212. The results show that miR-212 had a role in regulating HPA axis activity by modulating hypothalamic $\mathrm{CRH}$ expression. Data were presented as mean \pm S.E.M. $* P<0.05, * * P<0.01$, and $* * * P<0.001$ (vs group of NC at each time-point respectively). A full color version of this figure is available at http://dx.doi.org/10.1530/JME-17-0124.

early repressor (Shepard et al. 2005), and the signaling of endocannabinoid (Hill \& Tasker 2012). The complicated and precise networks of CRH regulators, however, are still not elucidated. Thus, it is meaningful to determine these networks to fully understand the regulation of HPA axis activity (Kovacs 2013, Gold 2015).

As verified by other research works, the HPA axis is activated when subjected to stressors and partly alleviated in long-term stress (Dallman 1993, Nyhuis et al. 2010a,b, Zimmerman et al. 2015). This study also shows that the HPA axis activity is partially returned to normal level when subjected to stressors for 14 days. By using a microRNA microarray analysis in the hypothalamus of mice subjected to heat stress, we found that miR-212, which is necessary for the proper development, maturation and function of neurons (Wanet et al. 2012), is capable of regulating CRH expression and HPA axis activity both in vitro and in vivo. As a concern, it was reported that dexamethasone treatment has no effect on miR-212 expression in rat adrenal glands (Hu et al. 2013) and level of pCREB and CREB in hypothalamic 4B cells (Evans et al. 2013). In our studies, the trend of corticosterone, which peaks at day 3 , and that of miR-212, which rises continuously in 14 days, also suggested that the expression of miR212 is independent of the stress-induced adrenal steroid. In addition, our results show that treatment of CREB-overexpressed cells with miR212 inhibitors resulted in higher levels of CRH expression compared with the CREB-overexpressed group, whereas the lower level of $\mathrm{CRH}$ expression was exhibited in the group treated with miR-212 mimics. These results suggest that miR-212 acts as a counter-regulatory factor in regulating CRH expression and HPA axis activity. Another explanation for the alleviation of HPA axis activity is habituation, which is a whole body response to rebuilding homeostasis during unlethal repeated stress. Our results showed that miR-212, which escalated during repeated stress, may be a part of

Published by Bioscientifica Ltd 
habituation processes since miR-212 could regulate HPA axis activity and level of serum corticosterone, which is important in adaptation and recovery from stress (Sapolsky et al. 2000, de Kloet et al. 2005, McEwen 2007). More important, because of the simultaneously synthesis of CRH and miR-212, we thought that regulation of miR-212 on CRH expression and HPA axis activity was prompt and efficient. Therefore, we proposed that once exposed to stress, a switch is turned on to activate the HPA axis but at the same time, a fuse (which miR-212 seems to be) is triggered to prevent overactivation of HPA axis (Fig. 5). Future studies will continue to explore the relationships among miR-212, HPA axis and habituation.

Currently, increasing numbers of people are threatened by excess HPA axis activity, especially those suffering from chronic physiological or psychological stress. Epidemiological investigations show that high levels of endogenous GCs, or treatment with exogenous GCs, are associated with adverse metabolic profile, increased cardiovascular disease and altered mood and cognitive decline (Reynolds 2013). Additionally, a major depressive disorder is characterized by an increased release of GCs and hyperactivity of the HPA axis (Keller et al. 2017). Other meaningful reports concluded that a decrease in miR-212 was linked with postpartum psychosis (Weigelt et al. 2013), mesial temporal lobe

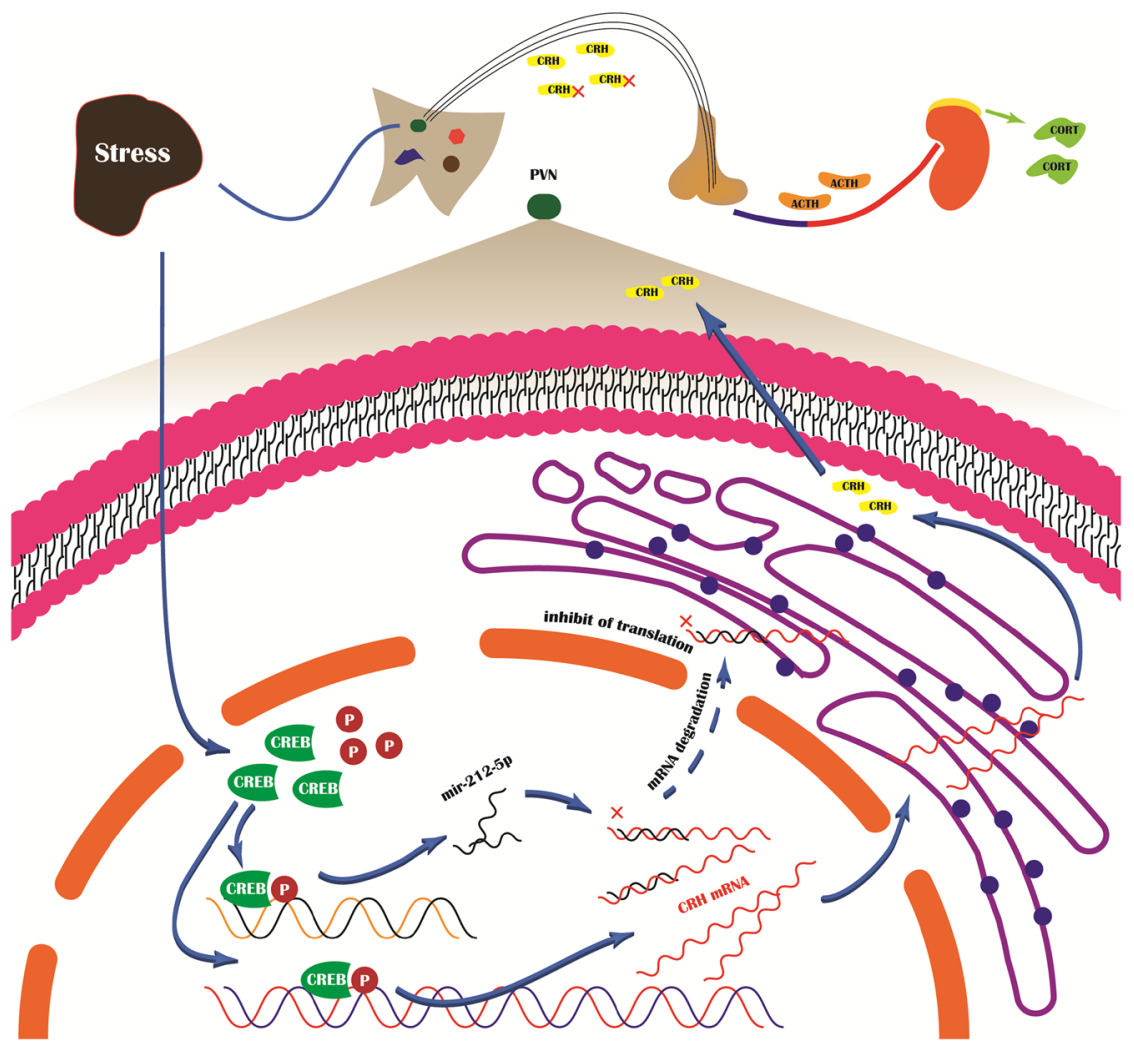

epilepsy (Haenisch et al. 2015) and Alzheimer's disease (Pichler et al. 2017). More significantly, dysregulation of miR-212 was associated with schizophrenia and bipolar disorders (Kim et al. 2010). Because our study indicates that inhibition of miR-212 leads to an increase in CRH expression and overactivity of the HPA axis both in vitro and in vivo, loss of miR-212 may be one of the reasons resulting in overactivity of the HPA axis and therefore may induce these mental disorders. The relationships among loss of miR-212, overactivity of the HPA axis and relative mental diseases deserve further investigation.

Another concern is that interventions for people who suffer from an overreactive HPA axis are lacking (Reiche et al. 2004, Wingenfeld \& Wolf 2011, Doom \& Gunnar 2013, Walker et al. 2016, Roelofs \& Pasman 2017). As a kind of gene-based therapy, many researchers are intrigued by microRNA therapy, and currently, these therapies are undergoing testing in clinical trials (Kasinski \& Slack 2011, Yin et al. 2014, Fernandez-Pineiro et al. 2017, Ji et al. 2017). Therefore, microRNA intervention may be a promising method to help people who suffer from an overreactive HPA axis as our study shows that overexpression of miR-212 could significantly reduce CRH expression and HPA axis activity in vitro and in vivo.

In conclusion, our study illustrates that microRNA participates directly in the regulation of the HPA axis
Figure 5

A counter-regulatory pathway is mediated by miR-212 to prevent overactivity of the HPA axis by regulating the $\mathrm{CRH}$ expression. A full color version of this figure is available at $\mathrm{http} / / / \mathrm{dx}$.doi. org/10.1530/JME-17-0124. http://jme.endocrinology-journals.org DOI: 10.1530/JME-17-0124
○ 2017 Society for Endocrinology Printed in Great Britain 
and suggests that miR-212 may be the link between overactivity of the HPA axis and relative diseases. Preventive or therapeutic measures based on miR-212 will be helpful for those people who suffer from the adverse effects of an overactive HPA axis.

\section{Declaration of interest}

The authors declare that there is no conflict of interest that could be perceived as prejudicing the impartiality of the research reported.

\section{Funding}

This research was supported in part by grants from Military 12th FiveYear Major Subject (\#AWS11J003-12): Estimate of adverse factors in naval environment and Development of medical preventive measures.

\section{Acknowledgement}

The authors thank Dr Chen Ling at Fudan University \& University of Florida for experiment design and article revision.

\section{References}

Bartel DP 2004 MicroRNAs: genomics, biogenesis, mechanism, and function. Cell 116 281-297. (doi:10.1016/S0092-8674(04)00045-5)

Charmandari E, Tsigos C \& Chrousos G 2005 Endocrinology of the stress response. Annual Review of Physiology 67 259-284. (doi:10.1146/annurev.physiol.67.040403.120816)

Chrousos GP \& Kino T 2007 Glucocorticoid action networks and complex psychiatric and/or somatic disorders. Stress 10 213-219. (doi:10.1080/10253890701292119)

Clarke R, Ressom HW, Wang A, Xuan J, Liu MC, Gehan EA \& Wang Y 2008 The properties of high-dimensional data spaces: implications for exploring gene and protein expression data. Nature Reviews Cancer 8 37-49. (doi:10.1038/nrc2294)

Dallman MF 1993 Stress update adaptation of the hypothalamicpituitary-adrenal axis to chronic stress. Trends in Endocrinology and Metabolism 4 62-69. (doi:10.1016/S1043-2760(05)80017-7)

de Kloet ER, Joels M \& Holsboer F 2005 Stress and the brain: from adaptation to disease. Nature Reviews Neuroscience 6 463-475. (doi:10.1038/nrn1683)

Di S, Malcher-Lopes R, Halmos KC \& Tasker JG 2003 Nongenomic glucocorticoid inhibition via endocannabinoid release in the hypothalamus: a fast feedback mechanism. Journal of Neuroscience $\mathbf{2 3}$ 4850-4857.

Doom JR \& Gunnar MR 2013 Stress physiology and developmental psychopathology: past, present, and future. Development and Psychopathology 25 1359-1373. (doi:10.1017/S0954579413000667)

Evans AN, Liu Y, Macgregor R, Huang V \& Aguilera G 2013 Regulation of hypothalamic corticotropin-releasing hormone transcription by elevated glucocorticoids. Molecular Endocrinology 27 1796-1807. (doi:10.1210/me.2013-1095)

Evanson NK \& Herman JP 2015 Role of paraventricular nucleus glutamate signaling in regulation of HPA axis stress responses. Interdisciplinary Information Sciences 21 253-260. (doi:10.4036/ iis.2015.B.10)

Evanson NK, Tasker JG, Hill MN, Hillard CJ \& Herman JP 2010 Fast feedback inhibition of the HPA axis by glucocorticoids is mediated by endocannabinoid signaling. Endocrinology 151 4811-4819. (doi:10.1210/en.2010-0285)
Felger JC \& Lotrich FE 2013 Inflammatory cytokines in depression: neurobiological mechanisms and therapeutic implications. Neuroscience 246 199-229. (doi:10.1016/j.neuroscience.2013.04.060)

Fernandez-Pineiro I, Badiola I \& Sanchez A 2017 Nanocarriers for microRNA delivery in cancer medicine. Biotechnology Advances $\mathbf{3 5}$ 350-360. (doi:10.1016/j.biotechadv.2017.03.00)

Glaser R \& Kiecolt-Glaser JK 2005 Stress-induced immune dysfunction: implications for health. Nature Reviews Immunology 5 243-251. (doi:10.1038/nri1571)

Gold PW 2015 The organization of the stress system and its dysregulation in depressive illness. Molecular Psychiatry 20 32-47. (doi:10.1038/mp.2014.163)

Gunn BG, Cunningham L, Mitchell SG, Swinny JD, Lambert JJ \& Belelli D 2015 GABAA receptor-acting neurosteroids: a role in the development and regulation of the stress response. Frontiers in Neuroendocrinology 36 28-48. (doi:10.1016/j.yfrne.2014.06.001)

Haenisch S, Zhao Y, Chhibber A, Kaiboriboon K, Do LV, Vogelgesang S, Barbaro NM, Alldredge BK, Lowenstein DH, Cascorbi I, et al. 2015 SOX11 identified by target gene evaluation of miRNAs differentially expressed in focal and non-focal brain tissue of therapy-resistant epilepsy patients. Neurobiology of Disease 77 127-140. (doi:10.1016/j. nbd.2015.02.025)

Haramati S, Navon I, Issler O, Ezra-Nevo G, Gil S, Zwang R, Hornstein E \& Chen A 2011 MicroRNA as repressors of stress-induced anxiety: the case of amygdalar miR-34. Journal of Neuroscience $\mathbf{3 1}$ 14191-14203. (doi:10.1523/JNEUROSCI.1673-11.2011)

Herman JP, McKlveen JM, Ghosal S, Kopp B, Wulsin A, Makinson R, Scheimann J \& Myers B 2016 Regulation of the hypothalamicpituitary-adrenocortical stress response. Comprehensive Physiology 6 603-621. (doi:10.1002/cphy.c150015)

Hill MN \& Tasker JG 2012 Endocannabinoid signaling, glucocorticoidmediated negative feedback, and regulation of the hypothalamicpituitary-adrenal axis. Neuroscience 204 5-16. (doi:10.1016/j. neuroscience.2011.12.030)

Hollins SL \& Cairns MJ 2016 MicroRNA: small RNA mediators of the brains genomic response to environmental stress. Progress in Neurobiology 143 61-81. (doi:10.1016/j.pneurobio.2016.06.005)

Hou J, Lin L, Zhou W, Wang Z, Ding G, Dong Q, Qin L, Wu X, Zheng Y, Yang Y, et al. 2011 Identification of miRNomes in human liver and hepatocellular carcinoma reveals miR-199a/b-3p as therapeutic target for hepatocellular carcinoma. Cancer Cell 19 232-243. (doi:10.1016/j. ccr.2011.01.001)

Hu Z, Shen WJ, Cortez Y, Tang X, Liu LF, Kraemer FB \& Azhar S 2013 Hormonal regulation of microRNA expression in steroid producing cells of the ovary, testis and adrenal gland. PLOS ONE 8 e78040. (doi:10.1371/journal.pone.0078040)

Ji W, Sun B \& Su C 2017 Targeting microRNAs in cancer gene therapy. Genes 8 E21. (doi:10.3390/genes8010021)

Kageyama K \& Suda T 2009 Regulatory mechanisms underlying corticotropin-releasing factor gene expression in the hypothalamus. Endocrine Journal 56 335-344. (doi:10.1507/endocrj.K09E-075)

Kasinski AL \& Slack FJ 2011 Epigenetics and genetics. MicroRNAs en route to the clinic: progress in validating and targeting microRNAs for cancer therapy. Nature Reviews Cancer 11 849-864. (doi:10.1038/nrc3166)

Keller J, Gomez R, Williams G, Lembke A, Lazzeroni L, Murphy GM Jr \& Schatzberg AF 2017 HPA axis in major depression: cortisol, clinical symptomatology and genetic variation predict cognition. Molecular Psychiatry 22 527-536. (doi:10.1038/mp.2016.120)

Kim AH, Reimers M, Maher B, Williamson V, McMichael O, McClay JL, van den Oord EJ, Riley BP, Kendler KS \& Vladimirov VI 2010 MicroRNA expression profiling in the prefrontal cortex of individuals affected with schizophrenia and bipolar disorders. Schizophrenia Research 124 183-191. (doi:10.1016/j.schres.2010.07.002)

Kovacs KJ 2013 CRH: the link between hormonal-, metabolic- and behavioral responses to stress. Journal of Chemical Neuroanatomy $\mathbf{5 4}$ 25-33. (doi:10.1016/j.jchemneu.2013.05.003)

Published by Bioscientifica Ltd. 
Kovacs KJ \& Sawchenko PE 1996 Sequence of stress-induced alterations in indices of synaptic and transcriptional activation in parvocellular neurosecretory neurons. Journal of Neuroscience 16 262-273.

Leung AK \& Sharp PA 2010 MicroRNA functions in stress responses. Molecular Cell 40 205-215. (doi:10.1016/j.molcel.2010.09.027)

McEwen BS 1998 Protective and damaging effects of stress mediators. New England Journal of Medicine 338 171-179. (doi:10.1056/ NEJM199801153380307)

McEwen BS 2007 Physiology and neurobiology of stress and adaptation: central role of the brain. Physiological Reviews 87 873-904. (doi:10.1152/physrev.00041.2006)

McEwen BS 2008 Central effects of stress hormones in health and disease: understanding the protective and damaging effects of stress and stress mediators. European Journal of Pharmacology 583 174-185. (doi:10.1016/j.ejphar.2007.11.071)

Meerson A, Cacheaux L, Goosens KA, Sapolsky RM, Soreq H \& Kaufer D 2010 Changes in brain MicroRNAs contribute to cholinergic stress reactions. Journal of Molecular Neuroscience $\mathbf{4 0}$ 47-55. (doi:10.1007/ s12031-009-9252-1)

Nahid MA, Yao B, Dominguez-Gutierrez PR, Kesavalu L, Satoh M \& Chan EK 2013 Regulation of TLR2-mediated tolerance and crosstolerance through IRAK4 modulation by miR-132 and miR-212. Journal of Immunology 190 1250-1263. (doi:10.4049/ jimmunol.1103060)

Nemoto T, Mano A \& Shibasaki T 2013 miR-449a contributes to glucocorticoid-induced CRF-R1 downregulation in the pituitary during stress. Molecular Endocrinology 27 1593-1602. (doi:10.1210/ me.2012-1357)

Nicolaides NC, Kyratzi E, Lamprokostopoulou A, Chrousos GP \& Charmandari E 2015 Stress, the stress system and the role of glucocorticoids. Neuroimmunomodulation 22 6-19. (doi:10.1159/000362736)

Nyhuis TJ, Masini CV, Sasse SK, Day HE \& Campeau S 2010a Physical activity, but not environmental complexity, facilitates HPA axis response habituation to repeated audiogenic stress despite neurotrophin mRNA regulation in both conditions. Brain Research 1362 68-77. (doi:10.1016/j.brainres.2010.09.038)

Nyhuis TJ, Sasse SK, Masini CV, Day HE \& Campeau S 2010b Lack of contextual modulation of habituated neuroendocrine responses to repeated audiogenic stress. Behavioral Neuroscience 124 810-820. (doi:10.1037/a0021203)

Paxinos G \& Franklin K 2003 The Mouse Brain in Sterotaxic Coordinates, 2nd Edn. Amsterdam, the Netherlands: Academic Press.

Pichler S, Gu W, Hartl D, Gasparoni G, Leidinger P, Keller A, Meese E, Mayhaus M, Hampel H \& Riemenschneider M 2017 The miRNome of Alzheimer's disease: consistent downregulation of the miR132/212 cluster. Neurobiology of Aging 50 167.e161-167.e110. (doi:10.1016/j.neurobiolaging.2016.09.019)

Reiche EM, Nunes SO \& Morimoto HK 2004 Stress, depression, the immune system, and cancer. Lancet Oncology 5 617-625. (doi:10.1016/S1470-2045(04)01597-9)

Remenyi J, Hunter CJ, Cole C, Ando H, Impey S, Monk CE, Martin KJ, Barton GJ, Hutvagner G \& Arthur JS 2010 Regulation of the miR212/132 locus by MSK1 and CREB in response to neurotrophins. Biochemical Journal 428 281-291. (doi:10.1042/BJ20100024)

Reynolds RM 2013 Glucocorticoid excess and the developmental origins of disease: two decades of testing the hypothesis - 2012 Curt Richter Award Winner. Psychoneuroendocrinology 38 1-11. (doi:10.1016/j. psyneuen.2012.08.012)

Rinaldi A, Vincenti S, De Vito F, Bozzoni I, Oliverio A, Presutti C, Fragapane P \& Mele A 2010 Stress induces region specific alterations in microRNAs expression in mice. Behavioural Brain Research 208 265-269. (doi:10.1016/j.bbr.2009.11.012)

Roelofs K \& Pasman J 2017 Stress, childhood trauma, and cognitive functions in functional neurologic disorders. Handbook of Clinical Neurology 139 139-155. (doi:10.1016/B978-0-12-801772-2.00013-8)

Sapolsky RM, Romero LM \& Munck AU 2000 How do glucocorticoids influence stress responses? Integrating permissive, suppressive, stimulatory, and preparative actions. Endocrine Reviews 21 55-89. (doi:10.1210/edrv.21.1.0389)

Seasholtz AF, Bourbonais FJ, Harnden CE \& Camper SA 1991 Nucleotide sequence and expression of the mouse corticotropin-releasing hormone gene. Molecular and Cellular Neuroscience 2 266-273. (doi:10.1016/1044-7431(91)90054-R)

Shepard JD, Liu Y, Sassone-Corsi P \& Aguilera G 2005 Role of glucocorticoids and cAMP-mediated repression in limiting corticotropin-releasing hormone transcription during stress. Journal of Neuroscience 25 4073-4081. (doi:10.1523/JNEUROSCI.0122-05.2005)

Silverman MN \& Sternberg EM 2012 Glucocorticoid regulation of inflammation and its functional correlates: from HPA axis to glucocorticoid receptor dysfunction. Annals of the New York Academy of Sciences 1261 55-63. (doi:10.1111/j.1749-6632.2012.06633.x)

Uchoa ET, Aguilera G, Herman JP, Fiedler JL, Deak T \& de Sousa MB 2014 Novel aspects of glucocorticoid actions. Journal of Neuroendocrinology 26 557-572. (doi:10.1111/jne.12157)

Vreugdenhil E, Verissimo CS, Mariman R, Kamphorst JT, Barbosa JS, Zweers T, Champagne DL, Schouten T, Meijer OC, de Kloet ER, et al. 2009 MicroRNA 18 and 124a down-regulate the glucocorticoid receptor: implications for glucocorticoid responsiveness in the brain. Endocrinology 150 2220-2228. (doi:10.1210/en.2008-1335)

Walker SE, Papilloud A, Huzard D \& Sandi C 2016 The link between aberrant hypothalamic-pituitary-adrenal axis activity during development and the emergence of aggression-animal studies. Neuroscience and Biobehavioral Reviews [in press]. (doi:10.1016/j. neubiorev.2016.10.008)

Wanet A, Tacheny A, Arnould T \& Renard P 2012 miR-212/132 expression and functions: within and beyond the neuronal compartment. Nucleic Acids Research 40 4742-4753. (doi:10.1093/ nar/gks151)

Weigelt K, Bergink V, Burgerhout KM, Pescatori M, Wijkhuijs A \& Drexhage HA 2013 Down-regulation of inflammation-protective microRNAs 146a and 212 in monocytes of patients with postpartum psychosis. Brain, Behavior, and Immunity 29 147-155. (doi:10.1016/j. bbi.2012.12.018)

Wingenfeld K \& Wolf OT 2011 HPA axis alterations in mental disorders: impact on memory and its relevance for therapeutic interventions. CNS Neuroscience and Therapeutics 17 714-722. (doi:10.1111/j.1755-5949.2010.00207.x)

Wright GW \& Simon RM 2003 A random variance model for detection of differential gene expression in small microarray experiments. Bioinformatics 19 2448-2455. (doi:10.1093/bioinformatics/btg345)

Yin H, Kanasty RL, Eltoukhy AA, Vegas AJ, Dorkin JR \& Anderson DG 2014 Non-viral vectors for gene-based therapy. Nature Reviews Genetics 15 541-555. (doi:10.1038/nrg3763)

Zeng Y, Wagner EJ \& Cullen BR 2002 Both natural and designed micro RNAs can inhibit the expression of cognate mRNAs when expressed in human cells. Molecular Cell 9 1327-1333. (doi:10.1016/S10972765(02)00541-5)

Zimmerman EC, Bellaire M, Ewing SG \& Grace AA 2015 Abnormal stress responsivity in a rodent developmental disruption model of schizophrenia. Neuropsychopharmacology 40 791. (doi:10.1038/ npp.2014.288)

Received in final form 1 September 2017

Accepted 13 September 2017

Accepted Preprint published online 14 September 2017 http://jme.endocrinology-journals.org

DOI: 10.1530/JME-17-0124
() 2017 Society for Endocrinology Printed in Great Britain
Published by Bioscientifica Ltd 